\title{
AUTISMO E OS DESAFIOS NO MERCADO DE TRABALHO
}

\section{ARTIGO DE REVISÃO}

GOMES, Leticia Ellen Florencio ${ }^{1}$

SCATOLIN, Henrique Guilherme ${ }^{2}$

GOMES, Leticia Ellen Florencio. SCATOLIN, Henrique Guilherme. Autismo e os desafios no mercado de trabalho. Revista Científica Multidisciplinar Núcleo do Conhecimento. Ano 05, Ed. 03, Vol. 09, pp. 153-168. Março de 2020. ISSN: 24480959, Link de acesso: https://www.nucleodoconhecimento.com.br/psicologia/autismoe-os-desafios

\section{RESUMO}

A inclusão social de pessoas com Transtorno do Espectro Autista (TEA) é imprescindível em todas as fases da vida, pois com a inclusão, o autista tem a oportunidade de desenvolver suas qualidades e autonomia. Considerando que estamos em um mercado de trabalho competitivo e as empresas estão cada vez mais exigentes, programas de inclusão se tornam fundamentais para o autista que necessita desta inserção para estimular suas capacidades e desenvolver suas habilidades e potencialidades. A partir de tais considerações, a presente pesquisa apresenta uma questão disparadora: quais os desafios de inclusão do autista no mercado de trabalho? Esta questão será discutida a partir de uma revisão bibliográfica, tendo por objetivo discorrer sobre a inclusão de pessoas com transtorno do espectro autista no mercado de trabalho, elaborar uma reflexão sobre a necessidade do olhar de inclusão de deficientes nas organizações, as políticas de inclusão e de como a psicologia pode contribuir para fortalecer e potencializar o R.H das empresas na questão da inclusão. Este estudo possibilitou reflexões sobre a

\footnotetext{
${ }^{1}$ Graduada em Psicologia, Pós graduada em Psicologia Organizacional e do Trabalho.

2 Doutor em Psicologia.
} 
inclusão do autista no mercado de trabalho considerando o olhar e as formas de gestão dessas pessoas no cotidiano laboral, estimulando a necessidade de se ter um olhar voltado as potencialidades além das limitações, para que habilidades sejam identificadas e estimuladas de forma inteligente, e acima de tudo respeitando os limites.

Palavras-chave: Autismo, inclusão, mercado de trabalho.

\section{INTRODUÇÃO}

De forma geral, o autismo (TEA- transtorno do Espectro Autista) é um transtorno global do desenvolvimento. Pessoas com este transtorno possuem certos tipos de déficits, excessos comportamentais e de desenvolvimento. As pessoas, neste espectro, podem ter diferentes graus de comprometimento, porém mais importante é que existem tratamentos afim de desenvolver habilidades em déficits, para que os comportamentos fiquem mais próximos do esperado para sua idade cronológica. Este transtorno tem particularidades, pois cada indivíduo tem dificuldades especificas; ou seja, o autismo é um universo singular e, muitas vezes, desconhecido (LEAR, 2004).

Sobre o diagnóstico do TEA, os especialistas alegam que este é complexo, pois o espectro é amplo e fluído, podendo apresentar diferentes formas e graus de comprometimento. (FITZQUERALD, 2013, apud AYDOS, 2016). O número de pessoas com este transtorno vem aumentando, porém há grandes dificuldades para se chegar ao diagnóstico. De acordo com a ONU, cerca de 1\% da população mundial algum transtorno do espectro autista. No Brasil estima-se que $1 \%$ da população tenha autismo e que $90 \%$ desses $1 \%$ não esteja diagnosticado (ONUBR, 2016). Esta pesquisa não tem intenção de se aprofundar no autismo em si, mas retratar e contextualizar alguns aspectos, para assim abordar o mesmo no mercado de trabalho.

Ouvimos muito falar em autismo na infância; mas e quando essas crianças crescem, o que acontece? Muitas terminam o ensino regular, até entram na faculdade, mas para entrar no mercado de trabalho, começar o primeiro emprego? A partir de tais considerações e indagações, a presente pesquisa se propõe a discorrer sobre a 
seguinte problemática: quais os desafios de inclusão do autista no mercado de trabalho?

A questão do mercado de trabalho no autismo, historicamente, ficava a cargo de ONGS, Associações, APAES e órgãos governamentais de assistência. Com o surgimento da lei de Inclusão, mais conhecida como lei de Cotas (Lei n 8213/91 de 24/07/1991) e a Lei no ,12.764, que conferiu o autismo como uma categoria de deficiência, resultou em um grande ganho pois o autismo foi considerado, por lei, como um tipo de deficiência mental e, consequentemente, as pessoas com esse transtorno passou a ser incluído na lei de cotas. De acordo com Oliveira (2017), a Lei 12.764 representou um marco histórico na luta pelos direitos dos autistas, de modo que tal inserção no campo das deficiências mentais proporcionou politicamente o acesso e garantia de direitos previstos na legislação de pessoas com deficiência do pais, como a garantia à inclusão em escolas regulares e mercado de trabalho, benefícios financeiros; entre outros. A Organização Mundial de Saúde, em 2011, fez uma declaração sobre a inserção social de pessoas com deficiências do tipo mental, ressaltando as dificuldades que enfrentam de inclusão, sendo o autismo umas das deficiências.

Apesar de existirem leis, legislações e políticas públicas que garantem a inclusão do autista no mercado de trabalho, ainda há dificuldade de inclusão no mundo laboral LEOPOLDINO, 2015).

Considerando que estamos em um mercado de trabalho competitivo e as empresas estão cada vez mais exigentes, este tipo de inclusão se torna um fator fundamental para os autistas que necessitam desta inserção para estimular suas capacidades e desenvolver habilidades. A profissionalização do PCD (Pessoa com Deficiência) / TEA estaria garantida pelas legislações trabalhistas, educacionais e especifica para TEA, mas apesar disso, muitos cargos foram criados só para preencher a porcentagem exigida pela lei (cotas), resultando, muitas vezes, a inclusão de pessoas qualificadas sem aproveitamento, sendo colocadas no mercado de trabalho para virarem estatísticas para as organizações e empresas. Sendo assim, há a necessidade de extrair o conceito coletivo existente de que deficiência é 
incapacitante e sinônimo de problema. Não podemos descartar que há algumas limitações, porém, há a necessidade de se olhar além das limitações, priorizando as habilidades que podem ser desenvolvidas.

Assim, a inclusão social do autista é essencial em todas as fases, pois com a inclusão, este tem a oportunidade de desenvolver suas potencialidades e autonomia. Ao se pensar em inclusão e no futuro dessas pessoas, se faz necessário pensar sobre a inclusão no mercado de trabalho, tema este que não vem sendo explorado em pesquisas, considerando que houve dificuldade em encontrar dados disponíveis nas bases de dados on-line e publicações que tratem desse tema, principalmente na área da Psicologia, sendo então de grande relevância pesquisas sobre este assunto para dar visibilidade a esta temática que vem sendo deixada de lado.

As pessoas dentro deste espectro podem possuir um conjunto de características, competências que, muitas vezes, podem agregar com o que as empresas necessitam, podendo carregar características importantes e habilidades muito especiais que precisam ser valorizadas e estimuladas, pois, muitas vezes, se tornam habilidades desconhecidas (LEOPOLDINO, 2015), visto que quando se fala no transtorno do autismo ou qualquer outra deficiência, as pessoas tem a visão de aquela imagem estereotipada ou pejorativa.

Conforme a problemática apontada, este estudo, a partir de uma revisão bibliográfica e perpassando pela Psicologia Organizacional, tem por objetivo suscitar reflexões acerca da inclusão de deficientes no mercado de trabalho, considerando a importância de se ter um R. H com olhar de inclusão e os desafios enfrentados na inserção de deficientes no mercado de trabalho.

De acordo com Dejous (1994), o trabalho pode ser fonte de prazer; uma vez que o trabalhador se identifica com o trabalho exercido, desenvolvendo capacidade de propor soluções, autonomia, resolver problemas, foco, disciplina, habilidades; entre outras. Deste modo, entendemos a importância e benefícios da inserção do sujeito no meio laboral. 
Considerando o quão positivo é o trabalho na vida do ser humano, é importante repensar como se dá o processo de inclusão do deficiente no mercado de trabalho. Acredita-se que é relevante que aconteça a inclusão cada vez mais, nas instituições e organizações, e que sejam garantidos como seus direitos, pois compreende- se que $o$ trabalho é fundamental para o desenvolvimento humano, inclusive para a sua inclusão social.

\section{METODOLOGIA}

A defasagem de publicações brasileiras a respeito do tema fez com que a pesquisa assumisse algumas características. A forma de abordagem do problema será exploratória e qualitativa, considerando os objetivos da pesquisa. Como procedimento técnico utilizará da pesquisa bibliografia e de levantamento, pois será uma pesquisa elaborada a partir de um material já publicado, através de livros, artigos e periódicos, fazendo uma revisão sobre o assunto (MINAYO,2000). Trata-se de uma pesquisa de caráter exploratório, pois visa proporcionar maior familiaridade com a temática abordada, tornando-a mais explicita (GIL,2002).

O trabalho de revisão de literatura é caracterizado como um:

[...]levantamento de toda a bibliografia já publicada, em forma de livros, revistas, publicações avulsas e imprensa escrita. Sua finalidade é colocar o pesquisador em contato direto com tudo aquilo que foi escrito sobre determinado assunto" (MARCONI \& LAKATOS, 2001, p. 43 - 44).

Nesta pesquisa busca-se discorrer sobre a inclusão de pessoas com transtorno do espectro autista no mercado de trabalho, refletir sobre a necessidade do olhar de inclusão de deficientes nas organizações e as políticas de inclusão bem como se a psicologia pode contribuir para fortalecer e potencializar o R.H das empresas na questão da inclusão[3].

Foram selecionados dissertações e artigos científicos que tratassem da temática em questão e temas relacionados. Os textos aqui estudados foram buscados em 
periódicos que tratasse sobre o autismo, sobre a inclusão de deficientes em psicologia organizacional e do trabalho, tendo como palavras chave: "inclusão de deficientes", "autismo" e "mercado de trabalho.". Os critérios para a escolha foram se os artigos abordavam o assunto inclusão de deficientes ou autismo no mercado de trabalho, como "inclusão de deficientes no mercado de trabalho" e "atuação da psicologia na inclusão de deficientes no mercado de trabalho". As reduzidas produções acadêmicas sobre a inclusão de pessoas com autismo no mercado de trabalho fizeram com que não fosse empregado recorte temporal, ou restrição para a seleção da literatura. A partir disso, foram selecionadas obras relacionadas ao tema que apresentassem coerência interna e rigor em sua elaboração, proveniente de instituições consideradas confiáveis.

\section{FUNDAMENTAÇÃO TEÓRICA}

O autismo é um tema pouco conhecido pela nossa sociedade. Se acordo DSM -V se trata de um Transtorno do Espectro do Autismo (TEA) e os pacientes são diagnosticados em graus de comprometimento. De acordo com o manual, o TEA é definido pela presença de déficits persistentes na comunicação, na interação social em múltiplos contextos e padrões repetitivos ou restritos de comportamento (DSM-V).

Este transtorno tem particularidades, pois cada indivíduo apresenta dificuldades específicas, ou seja, não é um transtorno singular, em alguns casos podendo ser incapacitante, mas em outros é possível que o indivíduo possa tem uma boa qualidade de vida, apresentando habilidades especiais que precisam ser valorizadas e, muitas vezes, são habilidades desconhecidas (LEOPOLDINO, 2015).

Os métodos diagnósticos disponíveis atualmente podem auxiliar na identificação precoce do transtorno. Sobre o diagnóstico do TEA, os especialistas alegam que é complexo, pois o espectro é amplo e fluido, podendo apresentar diferentes formas e graus de comprometimento (FITZQUERALD 2013 apud AYDOS, 2016).

O número de pessoas com o transtorno vem aumentando. Segundo dados do CDC (Center of Deseases Control and Prevention)[4], órgão ligado ao governo dos Estados 
Unidos, existe hoje um caso de autismo para cada 110 pessoas. Estima-se que no Brasil, com seus 200 milhões de habitantes, há cerca de 2 milhões de autistas, porém há grandes dificuldades para se chegar ao diagnóstico (EUA, 2018).

De acordo com Fitzgerald, (2013) apud Aydos (2016),

Em nossa sociedade, o rótulo de "autismo" parece estar sob o estigma do corpo perigoso e da mente fragilizada que, a qualquer alteração no ambiente, pode reagir imprevisivelmente, gerando uma desordem indesejada - noção estereotipada e homogeneizante, decorrente em grande parte por "não sabermos muito sobre ele", e menos ainda sobre "a pessoa com autismo e os detalhes prosaicos de sua vida diária" ( $p$. 397).

Neste sentido, é importante que se conheça muito bem sobre este transtorno, desconsiderando os rótulos impostos pelo senso comum, que corroboram ainda mais para um mundo de preconceitos, desvalorizando-os frente ao mercado de trabalho.

Embora este transtorno afeta algumas áreas do desenvolvimento, não impede que potencialidades sejam trabalhadas. Com treinamentos e tratamentos adequados as pessoas com autismo conseguem fazer a maioria das atividades da vida diária por conta própria e atingir um grau razoável de independência, as ações de tratamento consistem em terapia comportamental multidisciplinar especializada em transtornos do desenvolvimento e autismo, envolvendo psicólogos, terapeutas ocupacionais, fonoaudiólogos e psicopedagogos, entre outros profissionais. (FILIPE, 2013). Os tratamentos têm finalidade para desenvolver habilidades em todas as áreas do desenvolvimento.

As pessoas dentro do espectro podem possuir um conjunto de características, competências que, muitas vezes, podem agregar com o que as empresas necessitam, podendo carregar características importantes e habilidades muito especiais que precisam ser valorizadas e estimuladas. Leopoldino (2015) ressalta os potenciais empregadores que pessoas com TEA podem possuir como maior atenção 
aos detalhes, melhor facilidade em seguir regras e manter rotinas fixas, maior desenvoltura com funções repetitivas; preferência de ambientes visualmente organizados, trazendo ordem a ambientes desorganizados; maneira sistematizada de se organizar, favorecendo o ambiente de trabalho e as funções realizadas, excelente memorização em detalhes; menor taxa de atrasos, menor perda de tempo em conversas com colegas de trabalho ou chamadas telefônicas pessoais, maior fidelidade a um ambiente de trabalho em que há a existência de suporte e habilidade em se aprofundar e apresentar conhecimentos em áreas especificas pelas quais tenha um interesse especial. Pode-se inferir que as pessoas, dentro deste espectro, agregam um conjunto de características e competências que podem contribuir muito para o ambiente laboral.

As políticas públicas no processo de inclusão de autistas no mercado de trabalho criam uma estrutura legal de obrigações e estímulos que podem influenciar e auxiliar este processo. Mundialmente, o grande marco para impulsionar as políticas públicas foi a publicação em 2007 da convenção dos direitos das Pessoas com Deficiências (UNITED NATIONS, 2007). Esta convenção permitiu discussões, abriu espaço para a formulação e aprimoramento de políticas públicas e reconhecimento de direitos associados a inclusão de autistas no mercado de trabalho. Esta foi assinada por diversos países, inclusive o Brasil.

Em nosso país existe a lei que estabelece a Política Nacional de Proteção dos Direitos da Pessoa com Transtorno do Espectro Autista, a lei no 12. 764/12, que se constituiu em um marco legal, importante, pois o autismo foi considerado por lei como um tipo de deficiência mental e, consequentemente, as pessoas com esse transtorno passou a ser incluída na lei de cotas $n^{\circ} 8213 / 91$ na qual estabelece cotas para deficientes e pessoas com deficiência. Esta dispõe sobre os planos de benefícios da previdência e dá outras providências a contratação de portadores de necessidades especiais. A Lei de Cotas, foi e ainda pode ser considerado um passo importante para a inclusão destas pessoas no contexto de trabalho. De acordo com Oliveira (2017) a lei 12.764 representou um marco histórico na luta pelos direitos dos autistas de modo que tal inserção, no campo das deficiências mentais, proporcionou politicamente o acesso e 
garantia de direitos previstos na legislação de pessoas com deficiência do país, como garantia à inclusão em escolas regulares e mercado de trabalho, benefícios financeiros, entre outros. A Organização Mundial de Saúde, em 2011, fez uma declaração sobre a inserção social de pessoas com deficiências do tipo mental e ressaltou também as dificuldades que enfrentam de inclusão, sendo o autismo umas das deficiências.

Apesar de existirem leis, legislações e políticas públicas que garantem a inclusão do autista no mercado de trabalho, Leopoldino (2015) ressalta que os autistas ainda encontram dificuldade de inclusão no mundo laboral para obter empregos compatíveis com sua capacidade. Neste meandro é importante refletir sobre os efeitos das políticas de inclusão nas práticas de gestão e nos processos de subjetivação das pessoas com deficiência, para que tais leis perpassem do papel, possibilitando à construção simbólica e a prática de cidadania e voltada a "sensibilidades sociais" no Brasil (AYDOS, 2016).

A inclusão no mundo laboral para estes indivíduos, de acordo com Silva (2013), produz muitos benefícios, como por exemplo, uma melhor qualidade de vida, e permite ainda desenvolver potencialidades, acesso a outros espaços públicos de cultura, educação e lazer, promover a interação social, sendo o trabalho relevante para o alcance de metas pessoais do indivíduo, como a independência financeira, satisfação pessoal, visto que está diretamente ligado ao desenvolvimento dos direitos de cidadania, aumento da autoestima, ao reconhecimento por parte do outro que traz a aceitação pelos demais membros sociais e a valorização das potencialidades, sendo vista como pessoas capazes e produtivas.

O autor citado acima ainda ressalta que o trabalho se constitui em uma superação e emancipação do cidadão com deficiência que ultrapassa as diferenças quando está incluso, resgatando a independência do segmento e o respeito ante os demais. Mesmo com a relevância de se investir em estratégias de inclusão dentro das organizações, poucas são as empresas que parecem se preocupar com a qualidade destas inclusões .Silva (2013) destaca as grandes dificuldades relatadas pelas pessoas com TEA em relação ao mercado de trabalho, tais como as dificuldades em 
conseguir emprego e manter -se, a obtenção de uma colocação compatível com a sua capacidade e sua expectativa. Diante de algumas definições e contextualização exposta sobre o autismo, vale ressaltar que a pesquisa se refere a inclusão de pessoas com TEA no mercado laboral, no sentido de ressaltar a necessidade de se conhecer e buscar o apoio necessário para proporcionar a inclusão no universo do trabalho. Tal problemática ainda será discutida no decorrer deste artigo, com apoio de alguns autores, tais como Leopoldino (2015), Camargo (2014), Silva (2013), entre outros, que nos ajudam a discorrer sobre esta temática.

\section{RESULTADOS E DISCUSSÃO}

A questão da inclusão da pessoa com deficiência é complexa, principalmente se levarmos em consideração a forma em que nossa sociedade é estruturada, a qualidade de barreiras arquitetônicas que dificultam a convivência do deficiente em sociedade, além da pouca importância com que temas assim são tratados (MANTOAN, 1997).

A literatura sobre as novas formas de gestão em relação a inclusão social e diversidade cultural nas organizações estão mais ligadas ao campo da administração, para a análise de como as empresas estão lidando com a inclusão das pessoas com deficiência ou um ponto de vista crítico das desigualdades sociais no ambiente de trabalho e as resistências do universo empresarial brasileiro em aderir uma postura culturalmente inclusiva e socialmente responsável (AYDOS,2017).

De acordo com Leopoldino (2015):

A construção de uma cultura inclusiva e de suporte adequado permite que o potencial dos portadores de TEA possa se reverter efetivamente em trabalho e resultados, explorando os pontos fortes manifestados pelos profissionais autistas (p. 861).

Ambientes de trabalho sem suporte ou adaptações, desde ambientes físicos inadequados, a falta de postura dos gestores e colegas de trabalho, podem agravar a 
saúde mental de um autista, possibilitando que ocorra, no ambiente de trabalho, discriminações, perseguições, dificultando a adaptação ao trabalho, podendo tonarse inviável a atuação de muitos dos autistas no mercado de trabalho (LEOPLDINO, 2015).

Deste modo, há a importância de se olhar as necessidades da empresa e o manejo da equipe para o sucesso ou não da inclusão do autista no mercado de trabalho, uma vez que o R.H (voltado a inclusão) deve conhecer as características e as necessidades ambientais dos autista para assim desenvolver mecanismos de suporte em seu contexto de trabalho. O suporte adequado no ambiente de trabalho é uma das formas de tornar viável a inclusão ao trabalho para os portadores de TEA, além de amenizar as dificuldades (LEOPOLDINO, 2015).

Um exemplo de suporte em que o $\mathrm{RH}$ de uma empresa pode intervir é considerar o ambiente físico do trabalho, caracterizando-o com algumas necessidades do autista. Este ambiente pode sofrer modificações de modo a facilitar o seu trabalho, adotando estratégias nas estações de trabalho que facilitam e venham a minimizar comportamentos inadequados ou que prejudiquem a forma com que uma pessoa com TEA possa trabalhar. Leopoldino (2015) destaca ações como redução de luz e do barulho. Quando não tem a possibilidade de diminuir o barulho, possibilitar a liberdade para utilizar fones de ouvido. Assim, estas ações minimizam as distrações visuais, entre outras, uma vez que são medidas simples que podem tornar o ambiente mais propício ao autista. (LEOPOLDINO, 2015).

O estudo em relação ao desenvolvimento de ambientes com suporte ao trabalho dos autistas e também a avaliação de ajustes ambientais e impactos positivos desses ajustes e o bem-estar dos indivíduos portadores de TEA é um campo ainda novo e em formação (LEOPOLDINO, 2015). Assim, a inserção das pessoas com deficiência no mercado de trabalho implica em uma ampla rede de relações que se empenham no sentido de fazer com que tanto a organização quanto a pessoa com deficiência estejam preparados para constituir esta vinculação laboral. Neste sentido tanto os agentes estatais como a família, os funcionários da empresa e, principalmente, os 
gestores desempenham um papel fundamental para a garantia da inclusão, priorizando ajustes ao ambiente de trabalho.

Embora possa, à primeira vista, soar como tutelares e infantilizadoras, estamos diante de uma nova concepção de trabalho em que novas configurações de relações laborais se constituem a partir das políticas de inclusão. Para o seu sucesso há a necessidade de haver relações especificas que proporcionam o bem-estar daqueles que a recebem (AYDOS, 2017).

Diante dos enfrentamentos, desajustes e desafios postos à inclusão de deficientes no mercado de trabalho, a problemática deste artigo pode ser vista como um tanto provocativa quando questiona: quais os desafios de inclusão do autista no mercado de trabalho?

Para compreender a relação 'deficiência versus trabalho', evidenciando, neste contexto, os desafios e suas possibilidades, se faz necessário refletir sobre a necessidade do olhar de inclusão dos deficientes nas organizações e de como a Psicologia pode contribuir neste contexto, quais poderiam ser as suas contribuições para fortalecer e potencializar o $\mathrm{RH}$ das empresas na questão da inclusão.

Camargo (2014) destaca algumas ações do Psicólogo Organizacional que são facilitadoras no modo de promover e auxiliar no processo de inclusão de pessoas com deficiência, sendo o psicólogo um profissional capacitado e adequado para desenvolver atividades como o acolhimento, a integração, os acompanhamentos, os treinamentos, considerando não só por ter um preparo intelectual, mas também porque sua ciência e profissão (a Psicologia) está diretamente ligada a promoção de saúde em vários contextos, comprometida com a promoção e garantia de qualidade de vida dos indivíduos, sendo o trabalho um excelente contexto para promover saúde e qualidade de vida. Vale ressaltar, também, sobre o compromisso ético e cientifico com o desenvolvimento do ser humano e sua inclusão social. 
Sendo assim, o psicólogo pode atuar como facilitador da inclusão da pessoa com deficiência no mundo laboral, promovendo integração adequada, adaptação e qualidade de vida no trabalho.

Portanto, há um amplo legue de possibilidades de atuação da psicologia no ambiente organizacional como: comitês de inclusão, identificação de habilidades e o mapeamento de todas as funções dentro da empresa a fim de promover a adaptação, fazer a sensibilização dos funcionários e gestores, acompanhamento do trabalho, por meio de atividades e programas junto com a gestão de recursos humanos. Assim, é importante a utilização de técnicas e instrumentos que construa estratégias de integração, potenciais inclusivos e que visam aprimorar competências e habilidades (FILIPE, 2013)

\section{CONCLUSÃO}

Este estudo teve por objetivo discutir a inclusão de autistas no mercado de trabalho, ressaltando a necessidade do olhar de inclusão de deficientes nas organizações, explorando as políticas de inclusão e de como a psicologia pode contribuir para fortalecer e potencializar o R.H das empresas na questão da inclusão.

A revisão bibliográfica sobre esta temática revela um campo ainda em formação com uma grandeza de possibilidades e ampliação de estudo ainda pouco investigada por pesquisadores. De acordo com Leopoldino (2015) o estudo das dificuldades vivenciadas pelos autistas brasileiros no mercado de trabalho é praticamente nula. $A$ existência de informações detalhadas sobre o autismo, associado a inclusão no mercado de trabalho, permitiria que este ganho de conhecimento sobre este tema possibilitasse mais visibilidade ao tema, garantia e planejamento de políticas de inclusão mais eficazes com base na necessidade apresentada por esta população (LEOPOLDINO, 2015).

Contudo, destaca-se como limitação desta pesquisa o número reduzido de materiais que tratem diretamente sobre o tema no Brasil, mas esta limitação não impossibilitou que contribuições sobre o tema fossem feitas, como a reflexão sobre a inclusão do 
autista no mercado de trabalho, considerando o olhar e as formas de gestão dessas pessoas no cotidiano laboral, estimulando a necessidade de se ter um olhar voltado para as potencialidades além das limitações, para que habilidades sejam identificadas e estimuladas de forma inteligente e, acima de tudo, respeitando os limites.

Por conseguinte, como Ribeiro e Lima (2010) apontam sobre a evidencia de que não basta o Estado estabelecer leis de inclusão obrigando as empresas a admitirem pessoas com deficiência, é necessário que haja também empenhos por parte da sociedade e família junto as próprias empresas, na perspectiva de aumentar a compreensão sobre a realidade vivenciada por estas pessoas, aprendendo assim a lidar com as diferenças (RIBEIRO, LIMA, 2010).

Estes mesmos autores citados acima ressaltam que a inclusão do deficiente no mercado de trabalho resulta em uma exposição aos desafios e dificuldades, presentes no meio social mais amplo, tendo chances de crescer e desenvolver suas potencialidades. À medida que forem avançando poderão buscar cada vez mais competências, tornando-os mais capazes de responder as exigências e desafios do mercado de trabalho, reivindicando seus direitos e estabelecendo soluções para as suas dificuldades cotidianas.

\section{REFERÊNCIAS}

APA -AMERICAN PSYCHIATRIC ASSOCIATION. Manual diagnóstico e Estatístico de Transtornos Mentais-: DSM-5. Artmed Editora, 2014.

AYDOS, V. Agência e subjetivação na gestão de pessoas com deficiência: a inclusão no mercado de trabalho de um jovem diagnosticado com autismo. Horiz. antropol., Porto Alegre, v. 22, n. 46, p. 329-358, Dec. 2016 . Available from <http://www.scielo.br/scielo.php?script=sci_arttext\&pid=S0104$71832016000200329 \&$ Ing=en\&nrm=iso>. access on 12 May 2018. http://dx.doi.org/10.1590/S0104-71832016000200012. 
AYDOS, V. "Não é só cumprir as cotas": uma etnografia sobre cidadania, políticas públicas e autismo no mercado de trabalho. Horiz. antropol., Porto Alegre, v. 22, n. $46, p$.

329-358, 2017.

Disponível em:https://www.lume.ufrgs.br/bitstream/handle/10183/178166/001063580.pdf?seque nce=1\&isAllowed=y Acessado em: 15 de Jul. de 2018.

BRASIL. Lei 8.213/91. Brasília: Presidência da República, 2012.Disponivel em: http://www.planalto.gov.br/ccivil_03/LEIS/L8213cons.htm. Acesso em : 25 de jul. de 2018.

BRASIL. Lei 12.764/2012. Brasília: Presidência da República, 2012.Disponivel em: http://www.planalto.gov.br/ccivil_03/_ato2011-2014/2012/lei//12764.htm. Acesso em 22 de maio de 2018.

CAMARGO, M. L. O papel da psicologia organizacional e do trabalho no enfrentamento dos desafios à inclusão de pessoas com deficiência no mercado de trabalho. Mimesis, Bauru, v. 35, n. 2, p. 201-222, 2014.Disponivel em: https://secure.usc.br/static/biblioteca/mimesis/mimesis_v35_n2_2014_art_03.pdf. Acesso em: 01 de Set. de 2018.

CDC (National Center for Chronic Disease Prevention and Health Promotion), Prevalência de autismo ligeiramente maior na rede ADDM do CDC, 2018. Disponível em: $\quad$ https://www.cdc.gov/media/releases/2018/p0426-autism-prevalence.html. Acesso em: 21 de jul. de 2018.

DEJOURS, J. C. Psicodinâmica do trabalho: contribuições da escola dejouriana à análise da relação prazer, sofrimento trabalho. São Paulo: Atlas, 1994.

FILIPE,

$\mathrm{T}$.

M.

G.

As especificidades da orientação profissional em clientes com perturbaçõ es do espectro do autismo/síndrome deAsperger.

Dissertação (Mestrado em Psicologia) -Lisboa, UL -Universidade de Lisboa, 2013.Disponivel em: http://repositorio.ul.pt/handle/10451/10446. Acesso em: 5 de mai. De 2018. 
GIL, A. C. Como elaborar projetos de pesquisa. São Paulo: Atlas, 2002.Disponivel em: https://professores.faccat.br/moodle/pluginfile.php/13410/mod_resource/content $/ 1 /$ co mo_elaborar_projeto_de_pesquisa_-_antonio_carlos_gil.pdf. Acesso em: 5 de mai. De 2018.

LAKATOS, E. M.; MARCONI, M. A. Metodologia do trabalho científico: procedimentos básicos, pesquisas bibliográficas, projeto e relatório, publicações e trabalhos científicos. 5 ed. São Paulo: Atlas, 2001.

LEAR, K. Ajude-nos a Aprender. (Help us Learn: A Self-Paced Training Program for ABA Part 1:Training Manual). Traduzido por Windholz, M.H.; Vatavuk, M.C.; Dias, I.S.;Garcia Filho, A.P. e Esmeraldo, A.V.Canadá, 2004.

LEOPOLDINO, C. B. Inclusão de autistas no mercado de trabalho: Uma nova questão de pesquisa para os brasileiros. Gestão e Sociedade, v. 9, n. 22, p. 853-868, 2015.Disponivel em https://www.gestaoesociedade.org/gestaoesociedade/article/view/2033/1112. Acesso em: 14/05/2018.

MINAYO, M. C. de S.O desafio do conhecimento: pesquisa qualitativa em saúde. 7.ed. São Paulo: Hucitec; Rio de Janeiro: ABRASCO, 2000, p. 261 - 309

MANTOAN, Maria Teresa Eglér. A integração de pessoas com deficiência: contribuições para uma reflexão sobre o tema. São Paulo, SP: Memnon, 1997. $235 \mathrm{p}$.

OLIVEIRA, B. D. C. de et al . Políticas para o autismo no Brasil: entre a atenção psicossocial e a reabilitação1. Physis, Rio de Janeiro , v. 27, n. 3, p. 707726, July 2017 . Available from $<$ http://www.scielo.br/scielo.php?script=sci_arttext\&pid=S0103$73312017000300707 \&$ Ing=en\&nrm=iso>. access on 12 May 2018. http://dx.doi.org/10.1590/s0103-73312017000300017. 
ORGANIZAÇÃO MUNDIAL DA SAÚDE (OMS). Disability and Rehabilitation WHO Action Plan 2006-2011. Geneva: OMS. Disponível em:http://www.who.int/disabilities/publications/dar_action_plan_2006 to2011.pdf. Acessado em: 15 de Jul. de 2018.

ORGANIZAÇÃO DAS NAÇÕES UNIDAS (abril, 2016) Rejeitar pessoas com autismo é 'um desperdício de potencial humano', destacam representantes da ONU.Disponivel em: http://www.onu.org.br/index.php?s=autismo. Acesso em: 25 de jul. de 2018.

ORTEGA, F. Deficiência, autismo e neurodiversidade. Ciênc. saúde coletiva , Rio de Janeiro, v. 14, n. 1, p.67-77, fevereiro de 2009. Disponível em $<$ http://www.scielo.br/scielo.php?script=sci_arttext\&pid=S1413$81232009000100012 \&$ Ing=en\&nrm=iso>. acesso em 06 de setembro de 2018. http://dx.doi.org/10.1590/S1413-81232009000100012.

RIBEIRO, R. P. D. ; LIMA, M. E. A. O trabalho do deficiente como fator de desenvolvimento. Cad. psicol. soc. trab., São Paulo , v. 13, n. 2, p. 195207 , set. 2010 Disponível em

$<$ http://pepsic.bvsalud.org/scielo.php?script=sci_arttext\&pid=S1516$37172010000200004 \&$ Ing=pt\&nrm=iso >. acessos em 12 maio 2018.

SILVA,

A.

C.

M.

Autismo: o acesso ao trabalho como efetivação dos direitos humanos. Dissert ação (Mestrado em Direito) -Recife, UNICAP -Universidade Católica de Pernambuco, 2013.

UNITED NATIONS. Convention on the rights of people with disabilities. 2007. Disponível em: <http://www.un.org/disabilities/default.asp?id=150>. Acesso em: 18 de Jul. de 2018 .

3. Este trabalho foi aprovado pelo comitê de ética protocolo número 720/2018. 
4. CDC (National Center for Chronic Disease Prevention and Health Promotion), Prevalência de autismo ligeiramente maior na rede ADDM do CDC, 2018. Disponível em: https://www.cdc.gov/media/releases/2018/p0426-autism-prevalence.html

Enviado: Setembro, 2019.

Aprovado: Março, 2020. 